\title{
ASSESSMENT OF INDOOR AND OUTDOOR EXPOSURE TO AIRBORNE PARTICLES IN SUBWAY METRO STATIONS AND THEIR ASSOCIATED HEALTH RISKS
}

\author{
AMIT PASSI $^{1}$, SARAGUR M. SHIVA NAGENDRA ${ }^{1} \&$ M. PRAKESH MAIYA ${ }^{2}$ \\ ${ }^{1}$ Department of Civil Engineering, Indian Institute of Technology Madras, India \\ ${ }^{2}$ Department of Mechanical Engineering, Indian Institute of Technology Madras, India
}

\begin{abstract}
This investigative study examines the exposure of metro commuters to inhalable airborne particulate matter $\left(\mathrm{PM}_{10}, \mathrm{PM}_{2.5}\right.$, and $\left.\mathrm{PM}_{1}\right)$ in and around the subway premises, and their associated health risk due to regular exposure to high levels of PM. PM monitoring was carried out in five metro stations (four underground and one elevated) in Chennai, India. PM measurements were taken for 3 days a week (two weekdays and one weekend) in each metro station. The adverse impacts on health and the risk of disease were assessed using AIRQ+, a tool developed by World Health Organization (WHO). Exposure to PM was found to be up to twofold higher than the WHO stipulated safe limits. Exposure to $\mathrm{PM}_{2.5}$ was noted to be dominant (59\%-70\% of total PM mass). PM accumulation was found to be high in stations having a large number of commuters and those located in the busiest areas of the city. Infiltration of outdoor road emissions was found to have a significant influence on the deterioration of subway air quality. Underground metro stations were found to have the least dispersion and high accumulation of air pollutants whereas elevated metro stations were noted to have high dispersion and least accumulation. Health risk assessment indicated the non-carcinogenic risk to passengers (Hazard quotient $=1.18$ and Cancer risk $<10^{-4}$ ), who were exposed to PM regularly for a period of 1 year. Continuous, long-term exposure up to 8 years will lead to the development of carcinogenic risk (Hazard quotient $>10$ and Cancer risk $\left.>10^{-4}\right)$. Further, the health impact evaluation indicated high incidence per 100,000 population; asthma (816.92), unhealthy days (424.7), and lost workdays (416.57) due to acute exposure and ischemic heart disease (60.11), stroke (50), acute lower respiratory infections (30.52), and chronic obstructive pulmonary diseases (21.17) due to chronic exposure.
\end{abstract}

Keywords: subway stations, airborne particles, indoor exposure, outdoor exposure, health risk.

\section{INTRODUCTION}

In urban cities, residents spend a significant amount of time commuting between their home and workplace regularly. During their commute, they are inadvertently exposed to a variety of air pollutants on the roads, public, and private transportation modes they use. Subway metro is one of the fastest, cost-effective, convenient, reliable, and comfortable (airconditioned) public transport systems. Regional metro rail projects are developing at a fast pace and gaining a lot of popularity in recent years. The subway system has helped to substantially reduce the quantum of road traffic and their resultant noxious emissions. However, the intrinsic compact design, underground location, and airtight construction features of the subway system have posed new challenges in terms of poor indoor air quality (IAQ). Several studies conducted in the past have indicated that airborne particulate matter (PM) concentrations were usually high in indoor transport microenvironments [1]-[3]. Regular exposure to short-duration high-level PM concentrations results in adverse acute and chronic illnesses in passengers. Epidemiological and toxicological research investigations have shown a strong interconnection between PM exposure and severe health impacts [4], [5].

Several studies conducted in the past have reported PM exposure levels that were up to 10 times higher in subway stations than in the outdoor environment [6], [7]. The PM 
concentrations studied in the subway systems were associated with both indoor and outdoor environments. The underground and confined space of the metro favors infiltration of outdoor road emissions in addition to particles generated inside the metro [7]. The indoor sources of particle generation include abrasion of wheels and rails, sparking of electric wires, wear of brake pads, catenaries, and pantographs. Resuspension of particles due to the continuous to and fro activities of passengers and trains is another one of the main causes of sustained high levels of air pollutant concentrations. Several factors that influence particle concentrations in subway metro include the age of metro, design of tunnel and station, passenger density, frequency of trains, depth of station, wheel or rail track material, train speed, air-conditioning /ventilation system, frequency of station cleaning, etc. [8]. Due to the various operations of the metro, exposure to several $\mathrm{PM}_{2.5}$ metals such as $\mathrm{Fe}, \mathrm{Mn}, \mathrm{Mo}, \mathrm{Cu}$, $\mathrm{Ni}, \mathrm{Cr}, \mathrm{Ca}, \mathrm{Na}, \mathrm{Zn}$, and $\mathrm{Pb}$ was observed in metro stations [9], [10]. Thus, exposure of passengers to harmful airborne particles prevalent in the metro environment is a cause for concern that cannot be neglected. Inhalation of high concentrations of fine particles prevalent in the subway air results in their direct deposition in the lower respiratory system. Consequent to such exposure regularly, the deposited fine particles lead to the development of a variety of health symptoms. The different sizes of inhaled PM have the potential to impact passengers' health in different ways with varying degrees of severity [11]. The diameter of the PM is inversely proportional to the severity of health risk [12]. Exposure to airborne particles can have diverse short to long-term health issues such as respiratory infections, cardiovascular diseases, asthma, heart diseases, lung cancer, and mortality (WHO).

A comprehensive health impact assessment (HIA) procedure was developed by US EPA (Environmental Protection Agency). It defines the probability of occurrence of a particular health disease depending upon the duration of exposure to a pollutant. Further, WHO has developed a tool $\left(\mathrm{AIRQ}^{+}\right)$to calculate the health impacts of exposure to the contaminant of concern [13]. The present study aims to assess the exposure of metro passengers to PM in and around the subway premises, evaluate the health risks of exposure to high-level concentrations, calculate acute and chronic health impacts, and estimate the probability of disease.

\section{METHODS}

\subsection{Study area}

The air quality study was conducted in selected Chennai metro stations in India. Chennai is a bustling metropolitan city with an occupied area of $426 \mathrm{~km}^{2}$ and population of 11.23 million (2021). The metro system in Chennai became operational in July 2015. Chennai Metro is the third largest metro network in India with a current operational length of $54.15 \mathrm{~km}$. Chennai Metro has 19 elevated and 21 underground level metro stations carrying 1.25 lac passengers per day. Currently, two metro lines operate in the city; partially elevated and partially underground. Both metro lines serve to connect the urban areas of Chennai city. Line 1 connects the local areas of the city to the Airport and Line 2 connects to the Chennai Bus Depot and Central Railway Station. Fig. 1 presents the details of Chennai metro stations selected for the study.

\subsection{Monitoring and analysis of exposure to PM}

PM exposure concentrations were measured inside subway metro stations and around the premises of metro stations using Grimm spectrometer 1.109. Grimm spectrometer is a highly 


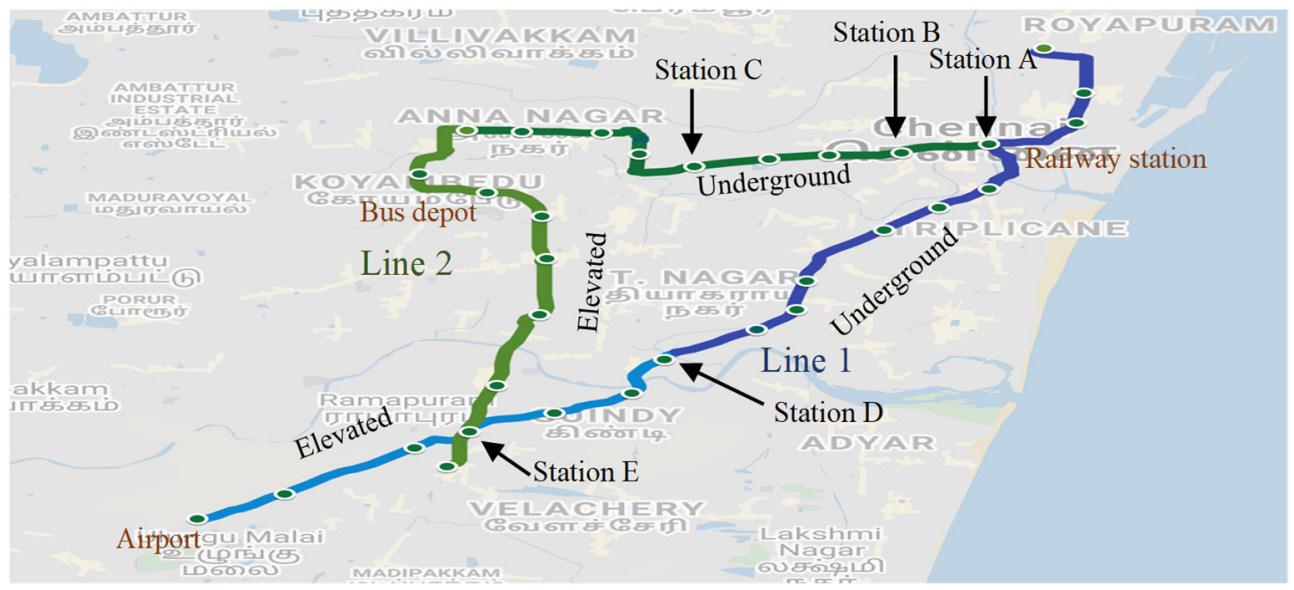

Figure 1: Chennai metro system and selected metro stations.

efficient and portable instrument used for collecting data on mass and number distribution of particles. In this study, the parameters considered were $\mathrm{PM}_{10}, \mathrm{PM}_{2.5}$, and $\mathrm{PM}_{1}$. Also, data was taken from the continuous ambient air quality monitoring station located in Alandur, which was installed by CPCB (cpcb.nic.in) for outdoor exposure assessment. The particle exposure monitoring was conducted in four underground metro stations selected from both lines and 1 elevated metro station. PM measurements were taken for 3 days a week (two weekdays and one weekend) in each metro station during March 2019. Each one-minute data was collected continuously for all 24 hours of the day. Data collected inside the metro stations and around the premises of metro stations were analyzed using descriptive statistics. The data is presented in the form of line graphs showing the hourly variation of data including standard deviation for both weekdays and weekends. Fig. 2 presents the location of measurements taken in and around subway premises. Inside metro stations, the measurements are representative of platform area and outside subway stations, measurements are representative of roadside areas around subway premises.

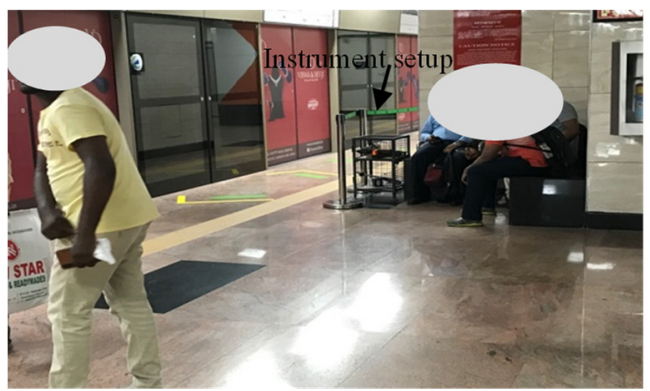

(a)

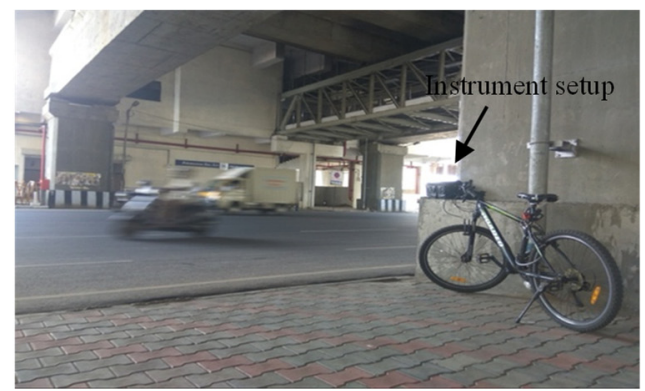

(b)

Figure 2: Location of measurements taken in and around subway premises. (a) Inside subway station; and (b) Outside subway station. 


\subsection{Assessment of health risk to passengers}

The health risk to the passengers due to the regular exposure to PM was analyzed based on the risk assessment guidance provided by US EPA. For health risk assessment, exposure to particles of size less than $2.5 \mu \mathrm{m}$ was considered, because particles in this size range easily penetrate the terminal bronchi and alveolar section of the human respiratory system, and after deposition are the causative factor for many adverse health problems. Particles of size 2.5$10 \mu \mathrm{m}$ penetrate the head and tracheobronchial regions but are easily expelled out from these regions in the course of everyday activities like coughing, sneezing, talking, laughing, and shouting. For the current study, non-carcinogenic risks of PM exposure were estimated using hazard quotient (HQ) and carcinogenic risk was estimated using cancer risk (CR).

\subsubsection{Non-carcinogenic risk}

Non-carcinogenic risk is the risk of occurrence of negative impact on the health of passengers due to regular high-level exposure to PM. The health risk in this category is not a causative factor for cancer. It is estimated as:

$$
H Q=\frac{C D I}{R f d},
$$

where, $C D I$ is chronic daily inhalation $(\mathrm{mg} / \mathrm{kg} /$ day) and $R f d$ is the reference dose of pollutant exposure ( $\mathrm{mg} / \mathrm{kg} / \mathrm{day})$.

$$
C D I=\frac{P M * I R * E D * E f * L E}{B W * A T L * N D Y} * P P F,
$$

where, $P M$ is particle mass $\left(\mathrm{mg} / \mathrm{m}^{3}\right), I R$ is particle inhalation rate $\left(\mathrm{m}^{3} /\right.$ hours $), E D$ is exposure duration (hours/week), $E f$ is exposure frequency (weeks/year), $L E$ is the length of exposure (years), $B W$ is bodyweight of passengers, $A T L$ is the average time of human life (years), NDY is the number of days per year (days/year), and $P P F$ is particle penetration factor.

$$
R f d=\frac{R f c * I R}{B W},
$$

where $R f_{c}$ is the reference dose of exposed air pollutant $\left(\mathrm{mg} / \mathrm{m}^{3}\right)$.

As per US EPA, $(\mathrm{HQ}<1)$ indicates no risk; $(\mathrm{HQ}>1)$ indicates non-carcinogenic risk; and $(\mathrm{HQ}>10)$ indicates high chronic risk.

\subsubsection{Carcinogenic risk}

Carcinogenic risk is the probability of occurrence of serious health impacts on passengers due to regular high-level exposure to PM that can cause cancer.

$$
C R=\frac{C D I}{C S F},
$$

where, $C S F$ is cancer slope factor $(\mathrm{kg}$ day $/ \mathrm{mg})$.

$$
C S F=I U R * \frac{B W}{I R} * 10^{3},
$$

where, IUR is inhalation unit risk of suspended particles $\left(\mathrm{m}^{3} / \mathrm{mg}\right)$.

As per US EPA, CR $<10^{-6}$ is considered acceptable for individual compounds, and $\mathrm{CR}<10^{-4}$ is considered acceptable as cumulative risk. 


\subsection{Evaluation of the impact of exposure to PM on the health of subway passengers}

The short-term and long-term health impacts on metro passengers were evaluated by deploying AIRQ+ software developed by WHO, using data collected from in and around the premises of subway stations. In the current study, the impact of continued exposure to PM and the consequent burden of disease have been quantified. The AIRQ+ software works with the epidemiological data of detrimental health impacts associated with prolonged exposure to air pollution. To evaluate the health impacts for present-day Indian conditions, the incidence rates of various acute health impacts such as respiratory diseases [14], cardiovascular diseases [14], asthma [15], and overall mortality [16], as well as chronic health impacts such as mortality due to ALRI [17], COPD [18], LC [19], IHD [20], and stroke [21] were taken from epidemiological research studies conducted in India. To calculate the estimated attributable incidences, reference values were taken as per WHO guidelines of PM exposure for an average of 24 hours; $\mathrm{PM}_{10}=50 \mu \mathrm{g} / \mathrm{m}^{3}$ and $\mathrm{PM}_{2.5}=25 \mu \mathrm{g} / \mathrm{m}^{3}$.

\section{RESULTS AND DISCUSSION}

\subsection{Exposure of passengers to PM}

Table 1 presents the PM concentrations that the passengers are exposed to inside and around the premises of subway metro stations. The data presented in Table 1 is the average of 3 days $(24 / 7)$ for each metro station.

Table 1: Exposure of passengers to airborne PM present inside and around the subway metro environment.

\begin{tabular}{|lccccccc|}
\hline \multirow{2}{*}{ Stations } & \multirow{2}{*}{ Variables } & \multicolumn{3}{c|}{ Inside subway stations } & \multicolumn{3}{c|}{ Around subway premises } \\
& & $\mathrm{PM}_{10}$ & $\mathrm{PM}_{2.5}$ & $\mathrm{PM}_{1}$ & $\mathrm{PM}_{10}$ & $\mathrm{PM}_{2.5}$ & $\mathrm{PM}_{1}$ \\
\hline \multirow{2}{*}{ Station A } & Mean & 80.98 & 54.38 & 40.24 & 103.00 & 61.47 & 48.48 \\
& $\mathrm{SD}$ & 24.46 & 12.40 & 7.81 & 41.00 & 19.09 & 13.36 \\
\multirow{3}{*}{ Station B } & Mean & 32.27 & 25.12 & 20.83 & 74.98 & 45.58 & 37.83 \\
& $\mathrm{SD}$ & 5.36 & 3.69 & 3.46 & 12.04 & 1.72 & 1.43 \\
\multirow{5}{*}{ Station C } & Mean & 23.18 & 17.36 & 14.07 & 49.11 & 29.66 & 23.73 \\
& $\mathrm{SD}$ & 8.47 & 6.35 & 5.31 & 21.87 & 10.76 & 8.61 \\
\multirow{2}{*}{ Station D } & Mean & 32.12 & 21.29 & 16.61 & 35.95 & 19.95 & 15.17 \\
& $\mathrm{SD}$ & 8.90 & 5.67 & 4.90 & 12.58 & 6.06 & 4.60 \\
\multirow{2}{*}{ Station E } & Mean & 47.32 & 29.90 & 24.58 & 90.21 & 53.89 & 42.03 \\
& $\mathrm{SD}$ & 8.69 & 4.01 & 3.18 & 33.07 & 14.72 & 11.48 \\
\hline
\end{tabular}

It can be observed from (Table 1) that the concentrations of PM were high around the premises of subway stations than inside metro stations. The highest concentrations of air pollutants were observed at Station A. Metro Station A is located in the central hub of Chennai. It is one of the busiest areas in the city. The overall ratios of outdoor/indoor PM concentrations were 1.75, 1.48, and 1.47 for $\mathrm{PM}_{10}, \mathrm{PM}_{2.5}$, and $\mathrm{PM}_{1}$, respectively (Table 2). The considerably high outdoor air pollutant concentrations indicate that road traffic emissions outside the subway could influence the indoor environment of the subway system.

Around the subway premises, the average $\mathrm{PM}_{2.5} / \mathrm{PM}_{10}$ ratio was 0.59 , and $\mathrm{PM}_{1} / \mathrm{PM}_{2.5}$ ratio was 0.79 . These ratios indicate that around subway premises, the total amount of PM 
Table 2: $\mathrm{PM}$ ratios; outdoor/indoor, $\mathrm{PM}_{2.5} / \mathrm{PM}_{10}$, and $\mathrm{PM}_{1} / \mathrm{PM}_{2.5}$.

\begin{tabular}{|lccccccc|}
\hline \multirow{2}{*}{ Stations } & \multicolumn{2}{c}{ Outdoor/Indoor } & \multicolumn{2}{c|}{ Inside subway stations } & \multicolumn{2}{c|}{ Around subway premises } \\
& $\mathrm{PM}_{10}$ & $\mathrm{PM}_{2.5}$ & $\mathrm{PM}_{1}$ & $\mathrm{PM}_{2.5} / \mathrm{PM}_{10}$ & $\mathrm{PM}_{1} / \mathrm{PM}_{2.5}$ & $\mathrm{PM}_{2.5} / \mathrm{PM}_{10}$ & $\mathrm{PM}_{1} / \mathrm{PM}_{2.5}$ \\
\hline Station A & 1.27 & 1.13 & 1.20 & 0.67 & 0.74 & 0.60 & 0.79 \\
Station B & 2.32 & 1.81 & 1.82 & 0.78 & 0.83 & 0.61 & 0.83 \\
Station C & 2.12 & 1.71 & 1.69 & 0.75 & 0.81 & 0.60 & 0.80 \\
Station D & 1.12 & 0.94 & 0.91 & 0.66 & 0.78 & 0.55 & 0.76 \\
Station E & 1.91 & 1.80 & 1.71 & 0.63 & 0.82 & 0.60 & 0.78 \\
\hline Average & 1.75 & 1.48 & 1.47 & 0.70 & 0.80 & 0.59 & 0.79 \\
SD & 0.53 & 0.41 & 0.39 & 0.06 & 0.04 & 0.02 & 0.03 \\
\hline
\end{tabular}
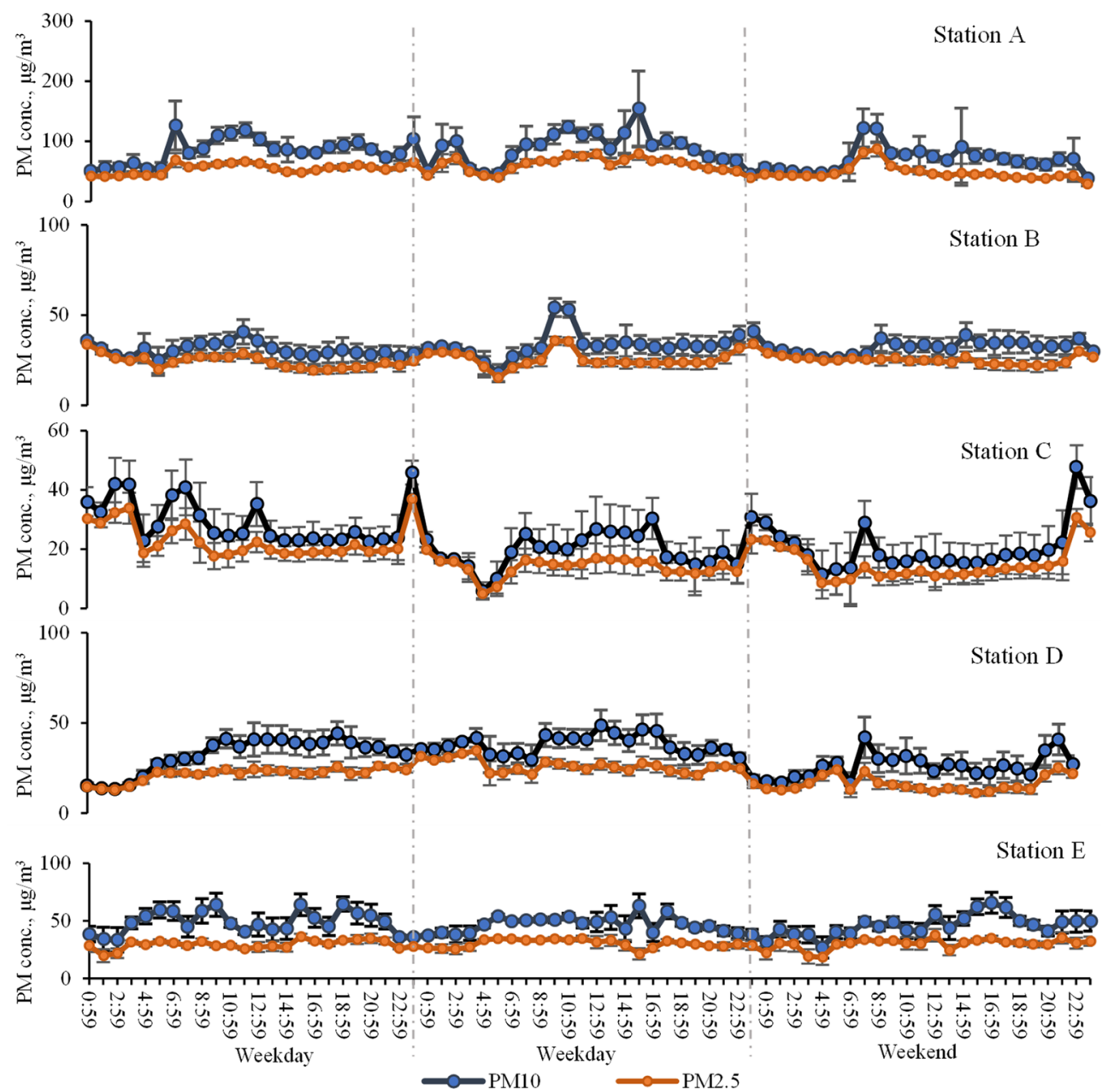

Figure 3: Hourly variations of particulate matter concentrations (conc.) inside studied subway metro stations during weekdays and weekends. 
comprised of $>59 \%$ particles of $<2.5 \mu \mathrm{m}$ size. The high composition of fine particles indicates the influence of road traffic vehicular exhaust emissions. Metro stations in Chennai city are situated on busy urban roads with substantially high daily average vehicular traffic.

Inside subway metro stations, the average $\mathrm{PM}_{2.5} / \mathrm{PM}_{10}$ ratio was 0.70 , and $\mathrm{PM}_{1} / \mathrm{PM}_{2.5}$ was 0.80 . These ratios indicate that inside metro areas, the total amount of PM comprised of $>$ $70 \%$ particles of the fine size range $(<2.5 \mu \mathrm{m})$. There are various sources of fine particles inside metro stations such as from tunnels (wear of rails, wheels, catenaries, and pantographs; service of metro lines; sparking of electric wires; wear of brake pads), resuspension due to the movement of trains and passengers, train piston force, and infiltration of outdoor fine particles suspended in the air [8]. Fig. 3 presents the hourly variations of PM inside subway metro stations during weekdays and weekends.

The average concentrations of PM $\left(\mathrm{PM}_{10}, \mathrm{PM}_{2.5}\right)$ during weekdays and weekends were (86.42, 57.71 and 70.09, 47.72), (32.32, 25.11 and 32.18, 25.12), (24.64, 18.68 and 20.27, 14.73), (35.16, 23.86 and 26.03, 16.14), and (47.85, 29.83 and 46.28, 30.05) for Stations AE, respectively. A notable difference of mean values was observed during weekdays and weekends in the stations having high daily average passenger travel $>5,000$ (Stations A and D) while the pollutant concentrations were almost similar in stations having low daily average passenger travel $<1,500$ (Stations B and C). Also, PM concentrations in the elevated metro station (Station E) were found to be almost similar during weekdays and weekends. One of the main reasons for the low and similar pollutant concentrations in elevated metro stations is direct interaction with the ambient environment and significant space for the dispersion of air pollutants. On the other hand, the highly closed and compact features of underground metro stations result in the least space for dispersion and a high accumulation of air pollutants.

Chennai metro operates from 5:27-23:05 hours on weekdays and 6:54-20:10 hours on weekends. Fig. 3 shows that the variation in the PM level commenced around 5:00 AM and continued till 23:00 hours after which a dip in concentration was observed till the metro operation resumed the next day. There was no notable difference observed for the variation of PM during peak (8:00-11:00 hours and 16:00-20:00 hours) and non-peak (11:00-16:00 hours) hours. The concentration variations were almost similar. This might be due to the suspension of fine particles for a longer duration in the air inside the metro stations because of prevailing environmental conditions. The concentration peaks in the figures indicate the activities of passengers at the metro stations.

Fig. 4 presents the hourly variation of PM around the premises of subway metro stations during weekdays and weekends. It can be observed from Fig. 4 that PM concentration variations around the premises of subway stations were comparatively high. The average concentrations of PM $\left(\mathrm{PM}_{10}, \mathrm{PM}_{2.5}\right)$ during weekdays and weekends were $(110.42,64.76$ and 88.16, 54.88), (75.67, 45.67 and 73.61, 45.42), (54.37, 32.55 and 38.58, 23.89), (34.17, 20.53 and $30.51,18.80)$, and $(88.98,52.53$ and $92.65,56.59)$ for Stations A-E, respectively. A notable difference in concentration values was observed for stations A and C. Station A is situated in the busiest area of the city and Station $\mathrm{C}$ is located in the commercial area (educational institute). Thus, due to the high activity during weekdays in comparison to weekends, notable variations were seen.

Thus, it is evident that high outdoor road $\mathrm{PM}_{2.5}$ emissions have a considerable influence on the indoor air quality of subway metro stations. Underground metro stations have the least dispersion and high accumulation of air pollutants whereas elevated metro stations have high dispersion and least accumulation. Metro stations featured with high daily average passenger travel and located in the busiest areas of the city were highly impacted by road emissions, 


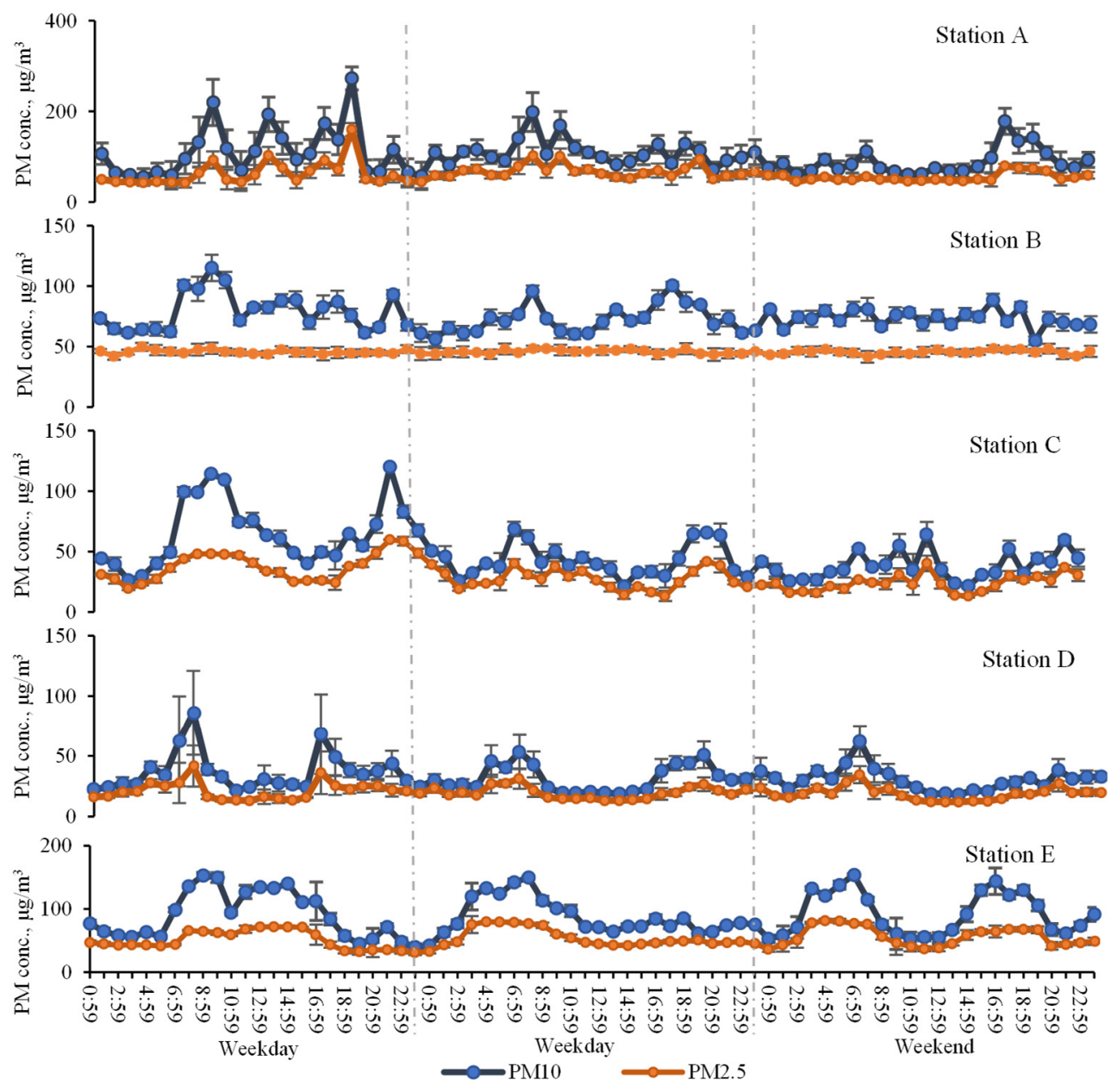

Figure 4: Hourly variation of particulate matter concentrations (conc.) around the premises of subway metro stations during weekdays and weekends.

passenger movement, and air pollutant accumulation. The least influence of passenger movement was observed in terms of peak and non-peak hours for metro stations with low to medium density of passenger flow.

\subsection{Health risk assessment of passengers}

\subsubsection{Health risk to passengers}

Regular exposure to substantially high air pollutant concentrations in and around the premises of subways can severely impact the health of passengers. For the calculation of health risk, PM mass was taken as per actual calculation (Table 1), IR was taken for light intensity work $($ sitting + walking operation $)=0.72(\mathrm{EPA}), \mathrm{ED}=10$ hours/week (Metro stations in Chennai city are mostly used by daily office workers. So, taken as 5 days $* 2$ hours per day travel), $\mathrm{Ef}=50$ weeks/year, $\mathrm{LE}=1$ year (calculated for 1-year regular exposure), 
$\mathrm{BW}=60 \mathrm{~kg}$ (as per average body weight of adult in India - ICMR-NIN), ATLT $=70$ years, $\mathrm{NDY}=70$ years, $\mathrm{PPF}=0.082$ [22], $\mathrm{Rfc}=0.025(\mathrm{WHO})$, and $\mathrm{IUH}=0.01$ [23]. Table 3 presents the health risk assessment of passengers exposed to high air pollutant concentrations in and around the subway premises.

Table 3: Health risk to passengers exposed to PM in the subway.

\begin{tabular}{|ccccccc|}
\hline \multirow{2}{*}{ Stations } & \multicolumn{3}{c}{ Inside subway stations } & \multicolumn{3}{c|}{ Around subway premises } \\
& CDI & HQ & CR & CDI & HQ & CR \\
\hline Station A & $1.04716 \mathrm{E}-06$ & 2.18 & $3.63598 \mathrm{E}-05$ & $1.18369 \mathrm{E}-06$ & 2.46 & $4.11003 \mathrm{E}-05$ \\
Station B & $4.8372 \mathrm{E}-07$ & 1 & $1.67958 \mathrm{E}-05$ & $8.77705 \mathrm{E}-07$ & 1.82 & $3.04759 \mathrm{E}-05$ \\
Station C & $3.3429 \mathrm{E}-07$ & 0.69 & $1.16066 \mathrm{E}-05$ & $5.71144 \mathrm{E}-07$ & 1.19 & $1.98301 \mathrm{E}-05$ \\
Station D & $4.09968 \mathrm{E}-07$ & 0.85 & $1.42341 \mathrm{E}-05$ & $3.84164 \mathrm{E}-07$ & 0.80 & $1.33382 \mathrm{E}-05$ \\
Station E & $5.75765 \mathrm{E}-07$ & 1.20 & $1.99906 \mathrm{E}-05$ & $1.03773 \mathrm{E}-06$ & 2.16 & $3.60298 \mathrm{E}-05$ \\
\hline Average & $5.70181 \mathrm{E}-07$ & 1.18 & $1.97974 \mathrm{E}-05$ & $8.10885 \mathrm{E}-07$ & 1.68 & $2.81549 \mathrm{E}-05$ \\
\hline
\end{tabular}

From Table 3, it can be seen that the average HQ is $>1$ and $<10$. It indicates the noncarcinogenic health risk of exposure to PM. As CR $<10^{-4}$, it indicates that cancer risk is within the acceptable limit ( $\mathrm{CR}<10^{-4}$ is considered because calculations are for $\mathrm{PM}_{2.5}$ as a whole; the composition includes multiple elements such as $\mathrm{Fe}, \mathrm{Mn}, \mathrm{Cu}, \mathrm{Ni}, \mathrm{Cr}, \mathrm{Ca}, \mathrm{Pb}$, etc.). It should be noted that here exposure risk is calculated for regular 1 year of exposure. The $\mathrm{HQ}$ and CR will increase with the increase in exposure duration. The overall average calculations showed that a continuous increase in the exposure duration up to 8.5 years resulted in $\mathrm{HQ}>10$ and $\mathrm{CR}>10^{-4}$. This may have severe long-term impacts on the health of passengers.

3.2.2 Evaluation of the impact of exposure to PM on the health of metro passengers

Table 4 presents the summary of acute health impacts that were calculated using AIRQ+ software for highly polluted metro station A. The PM data obtained for the areas in and around the subway metro premises surpassed the WHO stipulated guidelines for safe exposure levels in the air.

In Table 4, EAP (estimated attributable proportions), ENAC (estimated number of attributable cases), and ENAC-R (estimated number of attributable cases per 100,000 population at risk) are presented. The risk of asthma was found to be highest followed by restricted activity days and workdays lost (due to illness or deterioration in health).

\subsubsection{Burden of disease}

Prolonged exposure to high air pollutant concentrations can lead to chronic health impacts such as acute lower respiratory infections in children (ALRI), chronic obstructive pulmonary diseases (COPD), lung cancer (LC), ischemic heart disease (IHD), and mortality due to stroke. Table 5 presents the negative health impacts due to long-term PM exposure (burden of disease).

Observations from Table 5 indicate the highest prevalence of IHD followed by stroke mortality. There are also chances for children below age 5 to develop ALRI. LC has the lowest prevalence rate.

\section{CONCLUSIONS}

The rapid growth of the subway metro network at a global level in recent years has resulted in a marked increase in the number of passengers choosing this travel option. It has gained 
Table 4: Evaluation of health impact on exposure to PM in the premises of subway metro stations.

\begin{tabular}{|c|c|c|c|c|c|}
\hline Health impacts & $\begin{array}{l}\text { Incidence } \\
\text { rate }\end{array}$ & $\mathrm{RR}^{*}$ & $\operatorname{EAP}(\%)$ & ENAC & $\begin{array}{c}\text { ENAC-R } \\
(\text { per } 100,000)\end{array}$ \\
\hline Total mortality & 939.73 & $\begin{array}{c}1.0123 \\
(1.0045-1.0201)\end{array}$ & $\begin{array}{c}4.36 \\
(1.62-7)\end{array}$ & $\begin{array}{c}51 \\
(19-82)\end{array}$ & $\begin{array}{c}40.98 \\
(15.26-65.79)\end{array}$ \\
\hline $\begin{array}{l}\text { Hospital } \\
\text { admissions, } \\
\text { respiratory diseases }\end{array}$ & 932 & $\begin{array}{c}1.019 \\
(1-1.0402)\end{array}$ & $\begin{array}{c}6.63 \\
(0-13.39)\end{array}$ & $\begin{array}{c}77 \\
(0-156)\end{array}$ & $\begin{array}{c}61.83 \\
(0-124.78)\end{array}$ \\
\hline $\begin{array}{l}\text { Hospital } \\
\text { admissions, } \\
\text { cardiovascular } \\
\text { diseases }\end{array}$ & 882 & $\begin{array}{c}1.0091 \\
(1.0017-1.0166)\end{array}$ & $\begin{array}{c}3.25 \\
(0.62-5.83)\end{array}$ & $\begin{array}{c}36 \\
(7-64)\end{array}$ & $\begin{array}{c}28.66 \\
(5.45-51.40)\end{array}$ \\
\hline $\begin{array}{l}\text { Restricted activity } \\
\text { days }\end{array}$ & 2753.73 & $\begin{array}{c}1.047 \\
(1.042-1.053)\end{array}$ & $\begin{array}{c}15.42 \\
(13.93-17.17)\end{array}$ & $\begin{array}{c}531 \\
(480-591)\end{array}$ & $\begin{array}{c}424.70 \\
(383.68-472.73)\end{array}$ \\
\hline Work days lost & 2753.73 & $\begin{array}{c}1.046 \\
(1.039-1.053)\end{array}$ & $\begin{array}{c}15.13 \\
(13.02-17.17)\end{array}$ & $\begin{array}{c}521 \\
(448-591)\end{array}$ & $\begin{array}{c}416.57 \\
(358.63-472.73)\end{array}$ \\
\hline $\begin{array}{l}\text { Incidence of } \\
\text { asthma symptoms } \\
\text { (children) }\end{array}$ & 6000 & $\begin{array}{c}1.028 \\
(1.006-1.051)\end{array}$ & $\begin{array}{c}13.62 \\
(3.12-23.17)\end{array}$ & $\begin{array}{c}1021 \\
(234-1738)\end{array}$ & $\begin{array}{c}816.92 \\
(187.25-1390.47)\end{array}$ \\
\hline
\end{tabular}

$* \mathrm{RR}=$ relative risk with $95 \%$ confidence interval.

Table 5: Assessment of the burden of disease in subway metro passengers.

\begin{tabular}{|c|c|c|c|c|c|}
\hline Health impacts & $\begin{array}{l}\text { Incidence } \\
\text { rate }\end{array}$ & $\mathrm{RR}$ & EAP (\%) & ENAC & $\begin{array}{c}\text { ENAC-R } \\
(\text { per } 100,000)\end{array}$ \\
\hline $\begin{array}{l}\text { Mortality due to ALRI } \\
(0-5 \text { years) }\end{array}$ & 85.5 & 1.555 & $\begin{array}{c}35.69 \\
(27.99-43)\end{array}$ & $\begin{array}{c}38 \\
(30-46)\end{array}$ & $\begin{array}{c}30.52 \\
(23.93-36.76)\end{array}$ \\
\hline $\begin{array}{l}\text { Mortality due to COPD } \\
\text { (adults) }\end{array}$ & 64.7 & 1.486 & $\begin{array}{c}32.73 \\
(19.89-45.17)\end{array}$ & $\begin{array}{c}26 \\
(16-37)\end{array}$ & $\begin{array}{c}21.17 \\
(12.87-29.23)\end{array}$ \\
\hline $\begin{array}{l}\text { Mortality due to LC } \\
\text { (adults) }\end{array}$ & 6.9 & 1.359 & $\begin{array}{c}26.42 \\
(17.43-34.86)\end{array}$ & $\begin{array}{c}2 \\
(2-3)\end{array}$ & $\begin{array}{c}1.82 \\
(1.20-2.41)\end{array}$ \\
\hline $\begin{array}{l}\text { Mortality due to IHD } \\
\text { (adults) }\end{array}$ & 144 & 1.716 & $\begin{array}{c}41.74 \\
(24.81-58.21)\end{array}$ & $\begin{array}{c}75 \\
(45-105)\end{array}$ & $\begin{array}{c}60.11 \\
(35.73-83.82)\end{array}$ \\
\hline $\begin{array}{l}\text { Mortality due to stroke } \\
\text { (adults) }\end{array}$ & 145 & 1.526 & $\begin{array}{c}34.49 \\
(18.11-47.63)\end{array}$ & $\begin{array}{c}63 \\
(33-86)\end{array}$ & $\begin{array}{c}50 \\
(26.26-69.06)\end{array}$ \\
\hline
\end{tabular}

popularity as the preferred travel mode choice due to its advantageous features such as being fast, convenient, and comfortable. Based on the air quality study conducted in and around the premises of subway stations, it was identified that concentrations of PM were high around the premises of the subway in comparison to inside metro stations. Concentrations of PM surpassed the WHO recommendations of $50 \mu \mathrm{g} / \mathrm{m}^{3}$ and $25 \mu \mathrm{g} / \mathrm{m}^{3}$ for $\mathrm{PM}_{10}$ and $\mathrm{PM}_{2.5}$, respectively, in both environments. Exposure to fine particles was dominant both inside and around the metro premises ( $>59 \%$ of total PM mass). Air pollutant accumulation was found to be highest in stations with a high density of passengers and stations located in the busiest areas of the city. Infiltration of outdoor road emissions was found to have a considerable influence on IAQ deterioration. Underground metro stations were found to have the least dispersion and high accumulation of air pollutants whereas elevated metro stations were seen to have high dispersion and least accumulation. A notable difference in air pollutant concentrations was observed during weekdays and weekends in stations having a high daily 
average number of passengers travelling by metro. The least difference in air pollutant concentrations was noted during peak and non-peak hours because fine particles were dominant; they tend to remain suspended in the air for a longer duration. Thus, continuous operations of metro trains and the constant movement of passengers cause an elevated level of pollutant concentrations in the air throughout the day.

Health risk assessment of passengers due to regular high-level exposure to PM for 1 year indicated the $\mathrm{HQ}=1.18$, i.e., non-carcinogenic risk of exposure and $\mathrm{CR}$ was found to fall within the WHO limit of $10^{-4}$. Health impact evaluation of PM indicated the highest incidences (per 100,000) of asthma (816.92) followed by restricted activity days (424.7) and workdays lost (416.57). The least incidences were reported due to cardiovascular diseases and mortality $(<50)$. Further, the evaluation carried out to determine the burden of disease indicated the highest mortality (per 100,000 population) in adult passengers due to IHD (60.11) and stroke (50) followed by ALRI in children and COPD in adults, and least mortality due to $\mathrm{LC}(<2)$. It was also identified that regular exposure of metro passengers to high concentrations of airborne PM for a period of 8.5 years will result in carcinogenic risks $\left(\mathrm{HQ}>10\right.$ and $\left.\mathrm{CR}<10^{-4}\right)$.

\section{ACKNOWLEDGEMENT}

The authors would like to thank CMRL (Chennai Metro Rail Limited) for permitting us to conduct IAQ measurements inside subway metro stations.

\section{REFERENCES}

[1] Goel, R., Gani, S., Guttikunda, S.K., Wilson, D. \& Tiwari G., On-road $\mathrm{PM}_{2.5}$ pollution exposure in multiple transport microenvironments in Delhi. Atmospheric Environment, 123, pp. 129-138, 2015. https://doi.org/10.1016/j.atmosenv.2015.10.037.

[2] Yang, F. et al., Heterogeneity of passenger exposure to air pollutants in public transport microenvironments. Atmospheric Environment, 109, pp. 42-51, 2015. https://doi.org/10.1016/j.atmosenv.2015.03.009.

[3] Chan, L.Y., Lau, W.L., Lee, S.C. \& Chan, C.Y., Commuter exposure to particulate matter in public transportation modes in Hong Kong. Atmospheric Environment, 36, pp. 3363-3373, 2002.

[4] Valavanidis, A., Fiotakis, K. \& Vlachogianni, T., Airborne particulate matter and human health: Toxicological assessment and importance of size and composition of particles for oxidative damage and carcinogenic mechanisms. Journal of Environmental Science and Health - Part C, 26(4), pp. 339-362, 2008. https://doi.org/10.1080/10590500802494538.

[5] Dominici, F. et al., Fine particulate air pollution and hospital admission for cardiovascular and respiratory diseases. The Journal of the American Medical Association, 295(10), pp. 1127-1134, 2006.

[6] Barmparesos, N., Assimakopoulos, V.D., Assimakopoulos, M.N. \& Tsairidi, E., Particulate matter levels and comfort conditions in the trains and platforms of the Athens underground metro. AIMS Environmental Science, 3(2), pp. 199-219, 2016. https://doi.org/10.3934/environsci.2016.2.199.

[7] Martins, V. et al., Exposure to airborne particulate matter in the subway system. Science of the Total Environment, 511, pp. 711-722, 2015. https://doi.org/10.1016/j.scitotenv.2014.12.013.

[8] Passi, A., Nagendra, S.M.S. \& Maiya, M.P., Characteristics of indoor air quality in underground metro stations: A critical review. Building and Environment, 198, 107907, 2021. https://doi.org/10.1016/j.buildenv.2021.107907. 
[9] Ryswyk, K.V. et al., Metro commuter exposures to particulate air pollution and $\mathrm{PM}_{2.5^{-}}$ associated elements in three Canadian cities: the urban transportation exposure study. Environmental Science and Technology, 51(10), pp. 5713-5720, 2017. https://doi.org/10.1021/acs.est.6b05775.

[10] Aarnio, P. et al., The concentrations and composition of and exposure to fine particles $\left(\mathrm{PM}_{2.5}\right)$ in the Helsinki subway system. Atmospheric Environment, 39, pp. 5059-5066, 2005. https://doi.org/10.1016/j.atmosenv.2005.05.012.

[11] Khamraev, K., Cheriyan, D. \& Choi, J.-H., A review on health risk assessment of PM in the construction industry: Current situation and future directions. Science of the Total Environment, 758, 143716, 2021. https://doi.org/10.1016/j.scitotenv.2020.143716.

[12] Tian, G. et al., Indirect effect of $\mathrm{PM}_{1}$ on endothelial cells via inducing the release of respiratory inflammatory cytokines. Toxicology in Vitro, 57, pp. 203-210, 2019. https://doi.org/10.1016/j.tiv.2019.03.013.

[13] Miri, M. et al., Human health impact assessment of exposure to particulate matter: An AirQ+ software modeling. Enviro. Sci. Pollut. Res., 24, pp. 16513-16519, 2017. https://doi.org/10.1007/s11356-017-9189-9.

[14] Pascal, M. et al., Assessing the public health impacts of urban air pollution in 25 European cities: Results of the Aphekom project. Science of the Total Environment, 449, pp. 390-400, 2013. https://doi.org/10.1016/j.scitotenv.2013.01.077.

[15] Global Asthma Network, Global asthma report, 2018. www.globalasthmanetwork.org.

[16] World Health Organization, Health Impact Assessment of Air Pollution: Introductory Manual to AirQ+, Regional Office for Europe, 2020.

[17] Krishnan, A. et al., Epidemiology of viral acute lower respiratory infections in a community-based cohort of rural north Indian children. Journal of Global Health, 9(1), 010433, 2019. https://doi.org/10.7189/jogh.09.010433.

[18] Koul, P.A., Chronic obstructive pulmonary disease: Indian guidelines and the road ahead. Lung India: Official Organ of Indian Chest Society, 30(3), pp. 175-177, 2013. https://doi.org/10.4103/0970-2113.116233.

[19] Malhotra, R.K., Manoharan, N., Nair, O., Deo, S. \& Rath, G.K., Trends in lung cancer incidences in Delhi, India 1988-2012: Age-period-cohort and joinpoint analyses. Asian Pacific Journal of Cancer Prevention, 19(6), pp. 1647-1654, 2018. https/doi.org/10.22034/APJCP.2018.19.6.1647.

[20] Prabhakaran, D., Jeemon, P. \& Roy, A., Cardiovascular diseases in India: Current epidemiology and future directions. American Heart Association Inc., pp. 1605-1620, 2016. https://doi.org/10.1161/CIRCULATIONAHA.114.008729.

[21] Pandian, J.D. \& Sudhan, P., Stroke epidemiology and stroke care service in India. Journal of Stroke, 15(3), pp. 128-134, 2013. https://doi.org/10.5853/jos.2013.15.3.128.

[22] Asgharian, B., Hofmann, W. \& Bergmann, R., Particle deposition in a multiple-path model of the human lung. Aerosol Science and Technology, 34, pp. 332-339, 2001.

[23] Greene, N.A. \& Morris, V.R., Assessment of public health risk associated with atmospheric exposure to $\mathrm{PM}_{2.5}$ in Washington, DC, USA. International Journal of Environmental Research and Public Health, 3(1), pp. 86-97, 2006. 